\title{
In Memorium: Lee Goodglick
}

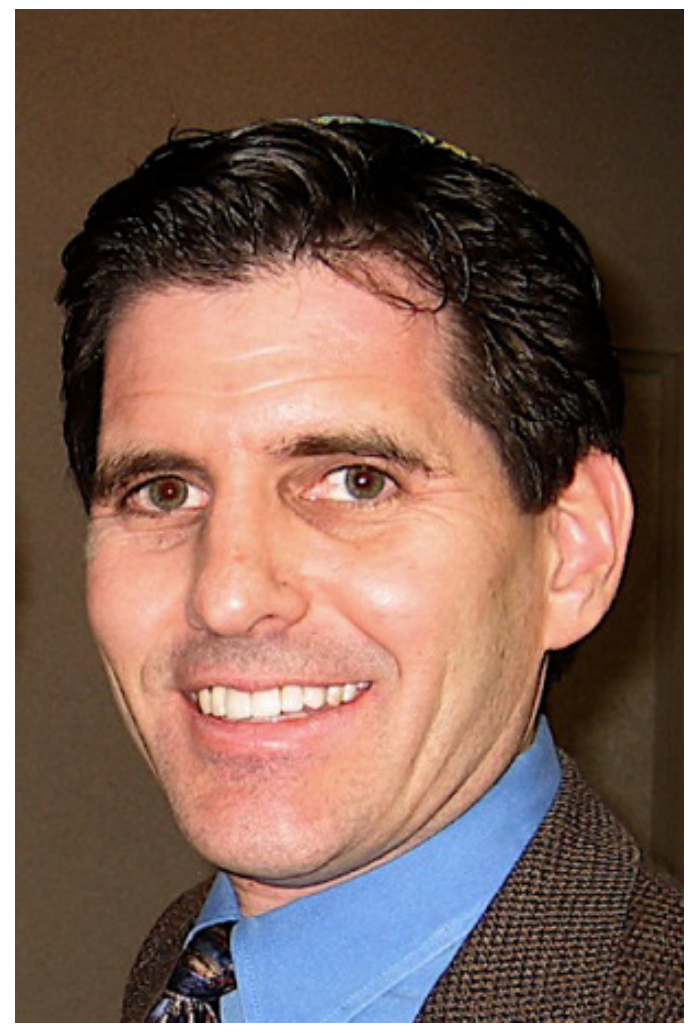

During his lifetime, Lee Goodglick never liked questions that did not have answers! Throughout his career as professor and molecular biologist at UCLA researching cancer, he was unrelenting in this pursuit of solutions. At age 54, ironically, he was stricken with the disease he had spent his profession striving to eradicate. He faced the challenge with tremendous strength and courage to the end.

When he died, Lee left a promising research project in the "clinical trial" stage, which if proven successful will assist lung cancer patients to extend their life spans. His medical colleague and dear friend continues the trials with hope for success.

This year, UCLA CTSI Seminar Series held its first annual Lee Goodglick Memorial Seminar in tribute to a weekly colloquium that Lee helped initiate nearly a decade ago, and frequently hosted. It fea- tured luminaries in science, medicine, government, education, industry, technology, public activism, the press, architecture, literature, and athletics. These included 16 Nobel Laureates, 82 members of the National Academy of Sciences, 11 best-selling authors, 17 chancellors, deans, and university presidents, and five members of national media organizations.

A serious-minded scientist, Lee had a gentle, compassionate, and sensitive spirit.

It is best exemplified by his own words by which he conducted himself and which are inscribed on his gravestone:

Family is not a burden, it's a blessing. Home is not a four letter word, it's a state of being. Love is not a salutation, it is an unconditional fact.

S. Goodglick \& W. Goodglick 